\title{
Estudo da complementaridade do comércio entre o Brasil e o Japão com vistas a um acordo de livre comércio
}

\author{
SILVIO Y. M. MIYAZAKI \\ NOBUAKI HAMAGUCHI*
}

\begin{abstract}
$\sqrt{2}$
Complementarity of trade between Brazil and Japan with a view to a free trade agreement. Japan has signed free trade agreements as trade policy since 2002 and three countries have already signed in Latin American. Considering the intention to carry out an agreement with Mercosur, this article aims to analyze the complementarities between Brazil and Japan trade structure by revealed comparative advantages indexes, with World Bank data for the period between 2006 and 2008. The results show a comparative advantage in primary commodities to Brazil and in industrial products to Japan, as well as indicating sectors that may oppose to trade liberalization.
\end{abstract}

Keywords: free trade agreement; Japan; comparative advantages.

JEL Classification: F15.

\section{INTRODUÇÃO}

Desde 1997 o Japão tem realizado uma política de comércio internacional ampla, negociando e firmando vários acordos de livre comércio, denominados pelo governo japonês como acordos de parceria econômica (APE). O primeiro a entrar em vigor foi o acordo com Cingapura em 2002, em seguida com o México em 2005. Além desse país latino-americano, mais dois outros dessa região têm

\footnotetext{
* Respectivamente, Professor Doutor da Escola de Artes, Ciências e Humanidades da Universidade de São Paulo. E-mail: symiyazaki@usp.br; Diretor do Research Institute for Economics and Business Administration da Kobe University. E-mail: hamaguchi@rieb.kobe-u.ac.jp. Agradecemos a Leonardo Baptista Correa pelo seu apoio no cálculo dos índices. Submetido: 22/fevereiro/2012; Aprovado: 9/ janeiro/2013.
} 
acordos de livre comércio com o Japão: o Chile desde 2007 e o Peru, que concluiu as negociações em 2011. Observa-se então uma clara ampliação da parceria econômica formal do Japão com países latino-americanos no que concerne ao comércio internacional, com três acordos de livre comércio já assinados nos últimos anos (Japan, 2011).

No que se refere aos acordos de livre comércio firmados pelo Mercosul com economias que estão fora do continente americano, o primeiro foi com Israel, que entrou em vigor em 2010, e o segundo ocorreu com o Egito, assinado também nesse mesmo ano. Há ainda os acordos de preferências tarifárias fixas com a Índia em vigência desde 2009 e com a União Aduaneira da África Austral, ${ }^{1}$ que foi concluído em 2009. Entretanto, ainda não há nenhum acordo comercial formal em negociação com países do Leste Asiático (Brasil, 2011).

Em entrevistas realizadas pelos autores do presente artigo em janeiro de 2011 durante um período de pesquisas no Japão, um alto funcionário de um órgão ligado ao Ministério da Economia, Comércio e Indústria do governo japonês mencionou que o país estava predisposto a iniciar conversações primeiramente com o Brasil com vistas à geração de um acordo de livre comércio com o Mercosur. Do lado brasileiro havia essa disposição dez anos antes, mas não há nos últimos anos manifestação oficial nesse sentido. No caso dessa hipótese se concretizar, o Japão estaria em uma posição ativa quanto a essa demanda, enquanto o Mercosul, principalmente o Brasil, em uma posição passiva neste momento.

Por parte do Mercosul, somente é possível realizar um acordo de livre comércio se os quatro países-membros componentes acordarem juntamente a respeito do objeto. Entretanto, considerando que entre os quatro países-membros do Mercosul o Brasil tem uma participação de aproximadamente $85 \%$ do fluxo de comércio bilateral com o Japão, optou-se por restringir o escopo do estudo, que se refere ao tipo de bens negociados, somente entre Brasil e Japão com vistas a simplificar a análise sem, no entanto, incorrer em perdas de generalidades.

Nesse contexto, o presente artigo busca avaliar o resultado em termos de ganhos de comércio de um possível acordo de livre comércio entre Brasil e Japão com base em cálculos de índices de vantagens comparativas reveladas de Balassa (1965). A análise, no entanto, limita-se aos bens já comercializados e que estão sujeitas a diferentes barreiras tarifárias e não tarifárias.

Os índices das vantagens comparativas reveladas têm sido utilizados em diferentes estudos para analisar o impacto para os setores decorrente do comércio entre países, bem como para analisar o grau de complementaridade das estruturas de comércio dos países com vistas à constituição de áreas de livre comércio. Calfat e Flores (2006) identificam e mensuram potenciais ganhos do comércio para agentes e setores específicos no caso de haver uma plena liberalização do fluxo de bens entre o Mercosul e a União Europeia, fazendo uso desses índices. Vaillant e Ons

\footnotetext{
${ }^{1}$ Formado por África do Sul, Botsuana, Lesoto, Namíbia e Suazilândia, conhecido pela sigla SACU em inglês.
} 
(2003) também utilizam esta metodologia para estudar uma área de livre comércio entre os Estados Unidos e o Mercosul. Esses autores propõem que nas negociações sejam excluídas indústrias com grupos de interesses contrários a um dado acordo para que ele tenha menos obstáculos políticos para ser firmado. Como resultado uma lista de produtos dessas indústrias foi elaborada com base nesses índices. Idêntica metodologia foi reproduzida por Olivera (2010) para estudar as consequências de uma futura área de livre comércio entre o Mercosul e a Asean. ${ }^{2}$ Kume e Piani (2005) estudaram as possíveis consequências de um acordo de livre comércio entre o Brasil e os Estados Unidos com o advento da ALCA. ${ }^{3}$ Os autores avaliaram usando, modelo de equilíbrio parcial, as vantagens comparativas dos produtos exportados por esses dois países. Bender (2006) analisou a similaridade das vantagens comparativas entre 12 países da América, mostrando as diferenças entre os custos de integração na ALCA.

Para verificar se um bem tem vantagem comparativa num país, usa-se o índice de vantagem comparativa revelada de Balassa (1965), utilizando a metodologia de análise de Vaillant e Ons (2003). Conforme esta, um acordo de livre comércio propiciará resultados positivos de bem-estar com o aumento do comércio bilateral caso um bem tenha vantagem comparativa em um país e desvantagem comparativa em outro país. Se não houver essa combinação, mesmo com o livre comércio, não haverá grandes efeitos de bem-estar decorrentes do aumento do fluxo de comércio.

Ainda, em acordo com a metodologia de análise adotada neste artigo, caso o bem tenha vantagem comparativa em um país e ao ingressar no outro país enfrente uma alta tarifa para restringir a sua entrada, um acordo de livre comércio com a eliminação da tarifa poderá ameaçar o setor produtivo do bem em questão. Isso porque a redução de tarifa induzirá um grande ingresso de importados, assim, com a concorrência, a indústria nacional enfrentará redução de preços e diminuição da produção de forma a ser uma ameaça ao setor produtivo desse bem. Não existirá essa ameaça, gerada por um acordo de livre comércio, se a tarifa já for baixa para um bem com vantagem comparativa no parceiro comercial e essas importações tiverem uma desvantagem comparativa, assim como quando o bem já estiver protegido pela existência de uma tarifa alta e o bem não tiver vantagem comparativa no parceiro comercial. Por essa metodologia de análise, em uma negociação de um acordo de livre comércio entre o Brasil e o Japão, seria possível verificar quais são os setores produtores dos bens que seriam ameaçados. Portanto, para detectar essas indústrias optamos por utilizar os dados para mensurar os índices com o nível de agregação dos produtos de quatro dígitos do Sistema Harmonizado.

As seções que seguem são a descrição da estratégia metodológica, os resultados e as considerações finais.

\footnotetext{
${ }^{2}$ ASEAN é a sigla em inglês da Associação de Nações do Sudeste Asiático, composta de Brunei, Camboja, Cingapura, Filipinas, Indonésia, Malásia, Miamar, Tailândia e Vietnã.

${ }^{3}$ ALCA é a sigla da proposta da Área de Livre Comércio das Américas.
} 


\section{ESTRATÉGIA METODOLÓGICA}

Para analisar a estrutura de um país quanto às suas vantagens comparativas, foi utilizado neste estudo o índice de vantagem comparativa revelada de Balassa (1965), dado pela equação (1):

Sejam dois países, A e B, que estejam participando da negociação de um acordo de livre comércio, que poderia envolver mais $\mathrm{n}$ países sem perda de generalidade.

$$
V_{C R_{i}^{k}}=\frac{X_{i}^{k} / X^{k}}{X_{i}^{W} / X^{W}}
$$

Onde:

$X_{i}^{k}=$ exportações do bem i pelo país $\mathrm{k}$

$X^{k}=$ exportações totais do país $\mathrm{k}$

Portanto, $X_{i}^{k} / X^{k}$ representa a participação das exportações do bem i no total das exportações do país $k$.

$X_{i}^{W}=$ exportações do bem i no mundo

$X^{W}=$ exportações totais do mundo

Logo, $X_{i}^{W} / X^{W}$ representa a participação das exportações mundiais do bem i no total das exportações mundiais.

Caso $\operatorname{VCR} X_{i}^{k}>$, o bem i do país $\mathrm{k}$ tem exportações relativamente grandes em relação às mundiais.

E, para analisar a estrutura de um país quanto às suas desvantagens comparativas, empregaremos um índice utilizado em Vaillant e Ons (2003: 132), baseado no de Balassa (1965), dado pela equação (2):

$$
\operatorname{VCRM}_{i}^{k}=\frac{M_{i}^{k} / M^{k}}{M_{i}^{W} / M^{W}}
$$

Onde:

$M_{i}^{k}=$ importações do bem i pelo país $\mathrm{k}$

$M^{k}=$ importações totais pelo país $\mathrm{k}$

Portanto, $M_{i}^{k} / M^{k}$ representa a participação das importações do bem i no total das importações do país $\mathrm{k}$.

$M_{i}^{W}=$ importações do bem i no mundo

$M^{W}=$ importações totais do mundo

Logo, $M_{i}^{W} / M^{W}$ representa a participação das importações mundiais do bem i no total das importações mundiais.

Caso $V C R M_{i}^{k}>1$, o bem i do país $\mathrm{k}$ tem importações relativamente grandes em relação às mundiais.

Com esses dois índices, o de vantagem comparativa revelada $\left(V C R X_{i}^{k}\right)$ e o de desvantagem comparativa revelada $\left(V_{C R M}^{k}\right)$, podemos classificar os bens em quatro grupos: 
1. $V C R X_{i}^{k}>1, V C R M_{i}^{k}<1$, em que o bem i do país $\mathrm{k}$ tem uma vantagem comparativa revelada com exportações relativamente grandes e importações relativamente pequenas.

2. $V C R X_{i}^{k}>1, V C R M_{i}^{k}>1$, em que o bem i tem um intenso comércio intraindustrial, com exportações e importações relativamente grandes. ${ }^{4}$

3. $V C R X_{i}^{k}<1, V C R M_{i}^{k}>1$, em que o bem i tem uma desvantagem comparativa revelada com exportações relativamente pequenas e importações relativamente grandes.

4. $V C R X_{i}^{k}<1, V C R M_{i}^{k}<1$, em que o bem i tem um comércio difícil uma vez que as exportações e as importações são relativamente pequenas. ${ }^{5}$

\section{Classificação dos bens conforme a vantagem comparativa revelada e a desvantagem comparativa revelada}

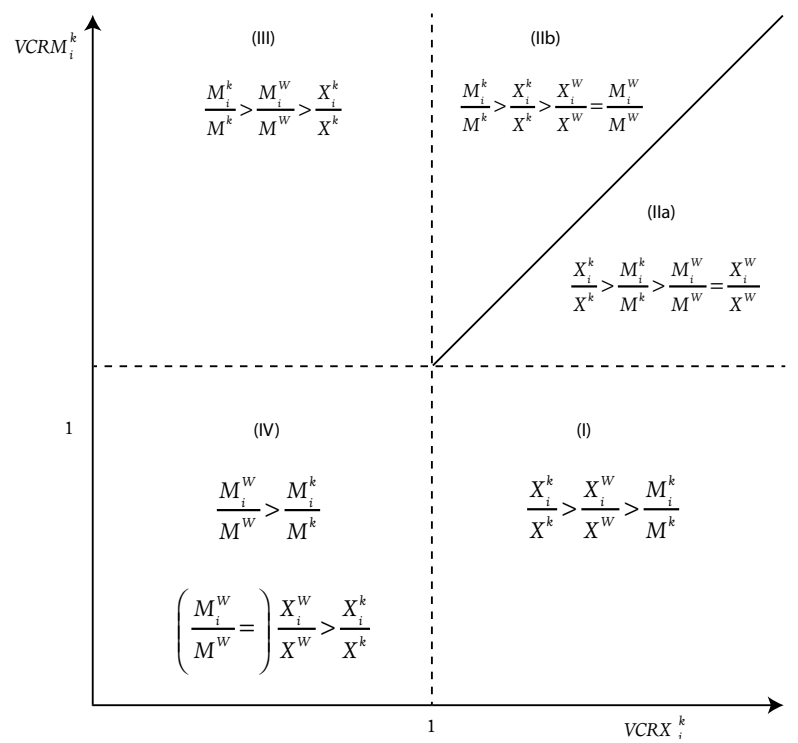

Fonte: Elaborado pelos autores

Realizada a classificação dos bens de cada um dos países, verificamos a relação de complementaridade da estrutura de comércio e os efeitos do livre comércio entre esses países, ilustrada pela Tabela 1.

Caso o bem seja do grupo (I) do país A e do grupo (II) ou do grupo (III) do país B, pode-se esperar um aumento das exportações desse bem do país A ao país

\footnotetext{
${ }^{4} \mathrm{O}$ grupo (II) pode ser subdividido em dois, em que $V C R X_{i}^{k}>V C R M_{i}^{k}$ seria o (II a) e $V C R X_{i}^{k}<V C R M_{i}^{k}$ seria o (II b), mas apenas vamos destacá-los, sem analisar essa diferença neste artigo.

${ }^{5}$ Altas tarifas, assim como outras barreiras como quotas e a existência de bens substitutos próximos, podem ser consideradas as causas das exportações e das importações serem relativamente pequenas nos bens do grupo (IV).
} 
B; o resultado será o mesmo para o bem que for do grupo (II) do país A e do grupo (III) do país B. Se o bem estiver no grupo (II) em ambos os países, haverá um aumento do comércio intraindustrial desse bem em ambas as direções. Nesses casos, pode-se esperar um resultado positivo do acordo de livre comércio uma vez que há uma relação complementar entre os dois países nesses bens.

Entretanto, se o bem for do grupo (I) em ambos os países, mesmo com o acordo de livre comércio não haverá aumento das importações do parceiro, pois são bens que competem diretamente nos mercados. $\mathrm{O}$ acordo de livre comércio para esses bens não terá grandes efeitos para o aumento do fluxo comercial entre esses dois países.

Se o bem for do grupo (III), portanto com desvantagem comparativa revelada, no país A e do grupo (III) ou do grupo (IV) no país B, o acordo de livre comércio também não resultará em ampliação do comércio bilateral.

Caso o bem seja do grupo (IV) do país A e seja do grupo (I) ou (II) do país B; se a dificuldade do comércio do país A for decorrente de altas barreiras tarifárias e não tarifárias, ou seja, protecionismo governamental ao setor, então há a possibilidade do surgimento de grupos de pressão e de interesse dos produtores desse bem que serão contrários às negociações de um acordo de livre comércio entre os dois países. Assim, esse bem poderia estar contido em uma lista de produtos que seriam excluídos da pauta de uma negociação de um acordo de livre comércio. Caso a dificuldade do comércio do país A seja por causa de barreiras naturais como custo do frete e do preço, mesmo com um acordo de livre comércio não haverá aumento das importações pelo país B.

Tabela 1: Matriz da relação de complementaridade da estrutura de comércio e dos efeitos de um acordo de livre comércio entre o País A e o País $\mathrm{B}$

\begin{tabular}{|c|c|c|c|c|c|c|c|}
\hline & \multicolumn{5}{|c|}{ País A } & \multirow{2}{*}{$\begin{array}{l}\text { Problemas políticos } \\
\text { ou poucos efeitos }\end{array}$} \\
\hline & & I & II a & $\mathrm{Il} b$ & III & IV & \\
\hline \multirow{5}{*}{ País B } & I & Concorrencial & & & & & \\
\hline & II a & & Espera-se & que haja re & tados & $\leftarrow$ & 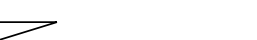 \\
\hline & II b & 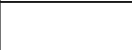 & (Complem & nentar) & & & \\
\hline & III & & & & Não h & efeitos & \\
\hline & IV & & $\leftarrow$ & & & & \\
\hline
\end{tabular}

Fonte: Elaborado pelos autores.

Em uma segunda etapa, tanto para o país A quanto para o país B são analisados os bens do grupo IV para verificar quais são os que têm barreiras tarifárias altas e que, portanto, podem ser sujeitas a grupos de pressão e de interesses contrários a um acordo de livre comércio.

\section{RESULTADOS}

Nesta seção, será analisada a estrutura e a relação de comércio do Brasil e do Japão através da metodologia apresentada anteriormente. Os dados utilizados pa- 
ra calcular os índices foram os bens com a agregação de produtos de quatro dígitos do Sistema Harmonizado. ${ }^{6}$ A escolha desse nível de agregação tem em vista o interesse em identificar e classificar os setores, não os produtos especificamente, quanto ao seu comércio. $\mathrm{O}$ resultado dos índices foi avaliado pela média simples dos índices das vantagens comparativas reveladas e das desvantagens comparativas reveladas de 2006, 2007 e $2008 .^{7}$

Quanto às barreiras tarifárias, foram utilizadas as tarifas equivalentes às da nação mais favorecida referentes ao ano de 2008.

Tanto os dados das exportações e das importações quanto as informações sobre tarifas foram coletados na base de dados World Integrated Trade Solution (http://wits.worldbank.org/) do Banco Mundial.

A Tabela 3, constante no anexo da versão eletrônica deste artigo, sintetiza os resultados dos índices de vantagem comparativa revelada $V C R X_{i}^{k}$ e de desvantagem comparativa revelada $\mathrm{VCRM}_{i}^{k}$, conforme o número de observações (produtos de quatro dígitos) em cada capítulo do Sistema Harmonizado e nos grupos (I), (II a), (II b), (III) e (IV), conceituados na seção anterior, para o Brasil e para o Japão. Com base na Tabela 3 foi possível construir a Tabela 2 abaixo, da matriz da relação de complementaridade da estrutura de comércio e dos efeitos de um acordo de livre comércio entre o Brasil e o Japão em 4 categorias.

Tabela 2: Matriz da relação de complementaridade da estrutura de comércio e dos efeitos de um acordo de livre comércio entre o Brasil e o Japão

\begin{tabular}{|c|c|c|c|c|c|c|}
\hline \multicolumn{2}{|c|}{} & \multicolumn{6}{c|}{ Brasil } \\
\cline { 2 - 8 } & I & II a & II b & II & IV \\
\hline \multirow{3}{*}{ Japão } & I & 26 & 16 & 17 & 109 & 89 \\
\cline { 2 - 8 } & II a & 3 & 1 & 3 & 26 & 25 \\
\cline { 2 - 8 } & II b & 2 & 0 & 0 & 8 & 13 \\
\cline { 2 - 8 } & III & 66 & 12 & 9 & 71 & 178 \\
\cline { 2 - 8 } & IV & 98 & 18 & 18 & 124 & 312 \\
\hline
\end{tabular}

Fonte: Elaborada pelos autores.

\section{A. Complementar}

Para a categoria de bens complementares, os países são julgados ter uma relação complementar no comércio quando um país A tem vantagem comparativa e o outro, país B, desvantagem comparativa nesses bens. Ao todo, nos dados de comér-

\footnotetext{
${ }^{6}$ Foram utilizados dados da classificação do Sistema Harmonizado na versão 2002.

${ }^{7}$ Para minimizar o efeito das flutuações anuais dos fluxos comerciais nos índices, empregou-se uma média aritmética dos índices de três anos. Muito embora houvesse dados de comércio de 2009 preferimos deixar de fora esse ano uma vez que houve a crise econômica que teve impacto negativo no comércio mundial, esse fato poderia distorcer a análise.
} 
cio entre Brasil e Japão, foram encontrados 272 bens nessa categoria. Os mais representativos de cada país são os da cadeia produtiva da indústria automobilística exportados pelo Japão e os produtos agrícolas e agroindustriais e minérios e metais exportados pelo Brasil. Ainda que estejam entre os principais produtos exportados pelo Brasil, alguns deles enfrentam um mercado fechado no Japão, tal como os dados tarifários mostram.

A1. (I) $x$ (II)

Dos 5 grupos de produtos investigados, somente um — hidrogênio, gases raros e outros elementos não metálicos -, que está na categoria (I) para o Brasil e está na (II) para o Japão, é representativo nas exportações brasileiras (US\$ 18,9 milhões) e enfrenta uma tarifa japonesa baixa (3,9\%).

No caso em que os produtos estão no (I) para o Japão e no (II) para o Brasil, uma série de produtos que são exportados do Japão ao Brasil enfrentam tarifas entre $16 \%$ e $18 \%$, entre esses, os que ultrapassam o valor exportado de U\$ 100 milhões são: partes e acessórios para veículos, motores e caixas de transmissão. Outros produtos, tais como pneus, motores e geradores elétricos e bombas de ar, vácuo e líquido; borracha sintética e artificial; além de papel, cartão, pasta de celulose, têm valores superiores a US\$ 10 milhões e inferiores a US\$ 100 milhões, enfrentando tarifas brasileiras de $12 \%$ e $20 \%$.

\section{A2. (I) $x$ (III)}

São 66 produtos que para o Brasil estão no (I) e para o Japão no (III). Das exportações brasileiras ao Japão destacam-se os itens com valores superiores a US\$10 milhões: soja e seus derivados; argila, minério de ferro e de manganês; lenha e madeira, pastas químicas de madeira; fios de seda; ferro fundido, níquel e alumínio bruto, que ingressam com tarifas baixas ou zero no Japão. Ceras vegetais e de abelha; preparações e conservas de carne, de miudezas, aves; sucos de frutas ou de produtos hortícolas; extratos, essências e concentrados de café, chá ou mate e suas preparações; álcool etílico enfrentam altas tarifas, acima de $10 \%$, chegando a $50 \%$.

São 109 produtos em que para o Japão estão no (I) e para o Brasil no (III). Das exportações japonesas ao Brasil, os maiores valores, ultrapassando os US\$ 100 milhões, são de impressoras, aparelhos de copiar e fax; partes e acessórios de motocicletas e bicicletas e rolamentos, com tarifas de 16\%. Entre US\$10 milhões e US\$ 100 milhões, os produtos são compostos químicos, chapas e filmes fotográficos; tubos e outras peças de borracha vulcanizada; trilhos e peças de vias férreas; ferramentas e peças de ferro ou aço; aparelhos e instrumentos mecânicos, e suas partes; máquinas, aparelhos e materiais elétricos e suas partes; aparelhos de gravação ou de reprodução de som e de imagens e suas partes e acessórios; instrumentos e aparelhos para área de saúde; motores; centrífugas; instrumentos e aparelhos para regulação ou controle, automáticos; guindastes; máquinas de costura e teares; máquinas-ferramentas; usinas e tornos que ingressam no Brasil com tarifas que variam entre $12 \%$ a $20 \%$.

A3. (II) $x$ (II)

São somente quatro produtos que estão nessa intersecção do mesmo grupo (II) 
em ambos os países. É pequeno o valor total do comércio desses produtos. O único produto representativo, no valor de US\$10,2 milhões, é de contadores, tais como taxímetros, velocímetros e estroboscópios, que são exportados do Japão ao Brasil, sofrendo uma tarifa de $18 \%$.

\section{A4. (II) $x$ (III)}

Ferroligas (US\$246,5 milhões e tarifa de 6,3\%), minérios de cobre e seus concentrados (US\$ 50,3 milhões e tarifa zero) e compostos aminados (US\$ 41 milhões e tarifa de 6,5\%) são os produtos com maiores valores que estão no grupo (II) para o Brasil e no grupo (III) para o Japão, que são exportados do Brasil ao Japão, enfrentando essas tarifas relativamente baixas.

Os produtos exportados do Japão ao Brasil que estão no grupo (II) para o Japão e no grupo (III) para Brasil, sofrendo tarifas entre 14\% e 16\% são as antenas (US\$ 69 milhões e tarifa de 16\%), compostos de nitrogênio (US\$ 46 milhões e tarifa de 14\%); aparelhos e máquinas de medida ou controle (US\$ 25,7 milhões e tarifa de $16 \%$ ); aparelhos e componentes de raios X e de outras radiações de uso da área da saúde (US\$ 23,4 milhões e tarifa de 14\%) e partes e acessórios para máquinas-ferramentas, assim como porta-peças e ferramentas (US\$ 17,1 milhões e tarifa de $14 \%$ ).

\section{B. Concorrencial}

Nessa categoria os bens em ambos os países têm vantagens comparativas, portanto concorrem diretamente, de forma que mesmo havendo um acordo de livre comércio o volume do comércio não deve aumentar.

B1. (I) $x$ (I)

Apenas 26 produtos estão nessa intersecção do mesmo grupo (I) em ambos os países. Os maiores valores das exportações brasileiras, mas inferiores a US\$ 10 milhões, nessa categoria são dos produtos semimanufaturados de ferro ou aço não ligado e de metais variados, tais como berílio, cromo, germânio, vanádio, gálio, háfnio, índio, nióbio, rênio e tálio, e seus derivados, sem nenhuma tarifa ou tarifa de baixo valor. A maior parte dessa categoria consiste de produtos laminados e derivados de ferro ou aço, com baixa tarifa ou nenhuma.

Já quanto às exportações japonesas, os produtos mais representativos são os motores de pistão de ignição (US\$ 38,1 milhões e tarifa de 18\%), laminados planos (US\$ 43,2 milhões e tarifa de $12 \%$ a $14 \%$ ), tubos, correntes e cadeias de ferro ou aço (US\$ 26,2 milhões e tarifa de 14\%). As exportações japonesas ao Brasil de tratores, veículos para transporte de mercadorias e chassis com motor têm um valor relativamente pequeno e enfrentam uma proteção tarifária de $35 \%$ ao ingressar no país; ainda que sejam bens com desvantagem comparativa para o Brasil, são indústrias protegidas por parte do governo brasileiro em particular e do Mercosul em geral, portanto são produtos que podem ser considerados como sensíveis, uma vez que não enfrentam concorrência do exterior. 


\section{Problemas políticos ou poucos efeitos}

Nessa categoria o bem tem vantagem comparativa em um país, ou seja, está no grupo (I) ou no grupo (II), e no outro país está no grupo (IV), pela política protecionista do parceiro comercial. Existem ameaças ao livre comércio, com a possibilidade de ser difícil chegar a um acordo, por pressão dos setores protegidos.

C1. (I) $\times($ IV)

São 98 produtos que para o Brasil estão em (I) e para o Japão estão em (IV). O produto mais significativo exportado pelo Brasil ao Japão é o algodão não cardado nem penteado (32,7 milhões e sem tarifa). Os seguintes produtos têm tarifas iguais ou maiores que $10 \%$; com valores entre US\$1,5 milhão e US\$ 8 milhões, couros preparados $(30 \%)$, calçados $(30 \%)$, chocolate $(29,8 \%)$, concentrados de proteínas e substâncias proteicas texturizadas $(29,8 \%)$; com valores inferiores a US\$ 0,6 milhão, couros e peles acamurçados, envernizados ou metalizados $(28 \%)$, farinha de milho $(25 \%)$, produtos de confeitaria sem cacau $(25 \%)$, peles com pelo curtidas ou acabadas $(20 \%)$, outros produtos de couro natural ou reconstituído $(18 \%)$ e pasta de cacau $(10 \%)$.

São 89 produtos que para o Japão estão em (I) e para o Brasil estão em (IV). Os produtos cujas exportações japonesas são maiores nessa categoria incluem automóveis de passageiros (US\$ 205,6 milhões e tarifa de 35\%), máquinas e aparelhos mecânicos (US\$ 105 milhões e tarifa de 18\%), circuitos integrados eletrônicos (US\$ 85,8 milhões e tarifa de $12 \%$ ), diodos, transistores e semicondutores (US\$ 53,9 milhões e tarifa de $12 \%$ ), motocicletas (US\$ 50,6 milhões e tarifa de 20\%), condensadores elétricos (US\$ 33,2 milhões e tarifa de 16\%), aparelhos transmissores para radiodifusão ou televisão, câmeras de televisão, câmeras fotográficas digitais e câmeras de vídeo (US\$ 28,5 milhões e tarifa de $20 \%$ ), tubos de ferro ou aço (US\$ 26,8 milhões e tarifa de $16 \%$ ), quadros para comando elétrico ou distribuição de energia elétrica e aparelhos de comando numérico (US\$ 15,7 milhões e tarifa de 18\%), ferramentas pneumáticas, hidráulicas ou com motor de uso manual (US\$ 13 milhões e tarifa de $20 \%$ ), discos, fitas, dispositivos de armazenamento de dados (US\$ 12,9 milhões e tarifa de 16\%), chapas, folhas, tiras e lâminas de plástico (US\$ 12 milhões e tarifa de $16 \%$ ). Cerca de $90 \%$ dos produtos dessa categoria têm tarifas de $10 \%$ a $35 \%$.

C2. (II) $x$ (IV)

Brasil (II) e Japão (IV)

O único produto com valor significativo (US\$ 19 milhões e tarifa de 30\%) é de couros e peles curtidos de bovinos ou de equídeos. Os outros produtos têm valores menores que US\$ 2,6 milhões, sendo que $80 \%$ deles têm tarifas menores que $10 \%$, não havendo produtos que sofram uma política comercial restritiva.

\section{Japão (II) e Brasil (IV)}

O único produto com valor significativo (US\$ 15,4 milhões e tarifa de 18\%) é o de máquinas e aparelhos elétricos com função própria, tais como aceleradores de partículas. Os outros produtos têm valores menores que US\$ 4,3 milhões, sendo que $80 \%$ deles têm tarifas entre $10 \%$ e $26 \%$. 


\section{Não há efeitos}

Nessa categoria, bens que os países não têm vantagem comparativa em especial, ao contrário, têm desvantagem comparativa, assim, um acordo de livre comércio trará poucos efeitos quanto ao aumento do comércio. Estão incluídos no grupo (IV) os produtos que são difíceis de comercializar por causa da proteção comercial, entretanto, não haverá ameaças em potencial caso esses bens não tenham vantagem comparativa no parceiro comercial.

\section{D1. (III) $\mathbf{x}$ (III)}

Nos produtos que estão em (III) para o Brasil e em (III) para o Japão, as exportações brasileiras enfrentam tarifas iguais ou acima de $20 \%$ : doces, geleias, marmeladas, purês e pastas de frutas, obtidos por cozimento (tarifa de $40 \%$ ); produtos hortícolas, preparados ou conservados, congelados (tarifa de 23,8\%); produtos hortícolas preparados ou conservados, não congelados (tarifa de $23,8 \%$ ); trigo e mistura de trigo com centeio (tarifa de $20 \%$ ). As maiores tarifas que as exportações japonesas enfrentam são iguais a $20 \%$ nos seguintes produtos: guarda-chuvas, sombrinhas e guarda-sóis; microfones, alto-falantes, fones de ouvido e amplificadores e aparelhos videofônicos de gravação ou de reprodução.

\section{D2. (III) $x$ (IV)}

Os produtos que estão no (III) para o Brasil e no (IV) para o Japão são 124; os exportados do Brasil ao Japão que enfrentam tarifas acima de $20 \%$ são: frutas e plantas em conservas (tarifa de 46,8\%); algas, beterraba-sacarina e cana-de-açúcar, caroços e amêndoas de frutos e de vegetais (tarifa de $40 \%$ ); queijos e requeijão (tarifa de $40 \%$ ); sorvetes (tarifa de 29,8\%); açúcares naturais ou químicos, xaropes de açúcar, derivados do mel (tarifa de 29,8\%); calçados impermeáveis de borracha ou plástico (tarifa de 27\%); vinhos de uvas frescas (tarifa de 25,5\%); massas alimentícias (tarifa de 23,8\%) e frutas congeladas (tarifa de 23,8\%).

São 178 produtos que estão no (III) para o Japão e no (IV) para o Brasil; os exportados do Japão para o Brasil que enfrentam tarifas iguais ou superiores a $30 \%$ são: alcoóis (tarifa de 30\%), tapetes (tarifa de 35\%), artigos de vestuário (35\%) e têxteis em geral (35\%).

\section{D3. (IV) $x($ IV)}

Nessa intersecção do mesmo grupo (IV), em ambos os países, os produtos brasileiros que enfrentam tarifas maiores que $20 \%$ são na maior parte produtos alimentícios, tais como manteiga, farinha e pastas de farinha, amido ou fécula, cereais, molhos, temperos e condimentos.

Os produtos japoneses que enfrentam tarifas maiores que $20 \%$ são quase na totalidade têxteis, tais como tapetes, roupa para esportes, cortinas, cortes de tecido e fios.

\section{CONSIDERAÇÕES FINAIS}

Este estudo teve como objetivo principal analisar a relação de complementaridade econômica do comércio entre Brasil e Japão com vistas a orientar negociações para um possível acordo de livre comércio. Para esta finalidade foi utilizada 
a metodologia das vantagens comparativas reveladas de Balassa (1965) aplicada em dados de comércio do Banco Mundial.

Os resultados obtidos podem contribuir para guiar estudos dos efeitos de possíveis aumentos nos fluxos de transações comerciais entre o Brasil e o Japão, caso se concretize uma negociação formal sobre essa zona de livre comércio.

Resumindo os resultados, o Brasil, que possui vantagens comparativas em produtos primários e nos seus derivados processados, e o Japão, que possui vantagens comparativas em diferentes tipos de produtos manufaturados, apresentam estrutura de comércio com características complementares. Dessa forma, um acordo de livre comércio seria benéfico a ambos em termos de aumento total de bem-estar.

Deve-se observar, entretanto, que para o Japão produtos como carnes bovina e suína, calçados, lácteos, farináceos, óleo de soja, folha de tabaco entre outros, e para o Brasil, produtos como veículos e uma parcela dos produtos têxteis, mesmo que os produtos tenham vantagem comparativa no parceiro comercial são protegidos por altas tarifas comerciais de forma que, na negociação de um acordo, há a possibilidade de haver oposição desses setores para a liberalização comercial devido às perdas que podem advir a essas indústrias com o livre comércio. Assim, para que seja mais fluida uma negociação de um acordo comercial entre o Brasil e o Japão, sugere-se que sejam retirados os produtos desses setores das listas de liberalização.

\section{REFERÊNCIAS BIBLIOGRÁFICAS}

Andreosso-O'Callaghan, B. (2009) “Economic structural complementarity: how viable is the Korea-EU FTA?", Journal of Economic Studies, 36-2: 147-167.

Balassa, B. (1965). “Trade Liberalisation and Revealed Comparative Advantage”. Manchester School of Economic and Social Studies, 33: 99-123.

Banco Mundial [World Bank]. "World integrated trade solution (WITS)" <http://wits.worldbank.org/ wits/>.

Bender,S. (2006). "Conflitos e convergências na ALCA numa perspectiva de vantagens comparativas reveladas de países das Américas”. Revista de Economia Aplicada, 10 (1): 111-135.

Brasil (2011). Disponível em <http://www.itamaraty.gov.br/o-ministerio/conheca-o-ministerio/america-do-sul/dnc-i-2013-divisao-de-negociacoes-extra-regionais-do-mercosul-i>. (Captado em $11 / 01 / 2012$ ).

Brasil. Ministério da Fazenda. Receita Federal (2011). Instrução Normativa RFB no 1.202. Anexo: Nomenclatura do Sistema Harmonizado.

Calfat, G. \& Flôres, R. G. (2006). "The EU-Mercosul Free Trade Agreement: Quantifying Mutual Gains”, Journal of Common Market Studies, 44: 921-94.

Hutchinson, G. A. \& Schumacher, U. (1994). "NAFTA's threat to Central American and Caribbean Basin Exports: a revealed comparative advantage approach", Journal of Interamerican Studies and World Affairs, 36(1):127-148.

Japan (2011). Disponível em <http://www.mofa.go.jp/policy/economy/fta/index.html (Captado em 11/01/2011).

Kume, H. \& Piani, G. (2005). "ALCA: uma estimativa do impacto no comércio bilateral Brasil-Estados Unidos”, Economia e Sociedade, 17(2): 215-233.

Olivera, M. (2010). "Ganadores y perdedores em um área de libre comercio”. Documento de Trabajo/ Premio Jovenes no. 4. Red Mercosur.

Vaillant, M. \& Ons, A. (2003). "Winners and losers in a free trade area between the United States and Mercosur” In: Lorenzo, F. \& Vaillant, M. (ed.). Mercosur and the Creation of the Free Trade Area of the Americas. Washington: Woodrow Wilson International Center for Scholars. 